\title{
Effect of Different Chemical Treatments on Germination of Strawberry Seeds
}

\author{
Suman Lata", Girish Sharma, Sourabh Garg and Munmun Joshi \\ UAIS Chandigarh University, Gharuan-Mohali, India \\ Department Fruit Science, Dr Y S Parmar University of Horticulture and Forestry, \\ Himachal Pradesh-173230, India \\ *Corresponding author
}

\section{A B S T R A C T}

Keywords

Strawberry, Seed germination, Ethrel, Gibberellic acid, $\mathrm{H}_{2} \mathrm{SO}_{4}$

Article Info

Accepted:

10 February 2018 Available Online:

10 March 2018
All the chemical treatments resulted in significantly higher strawberry seed germination over control. Ethrel 5000 ppm recorded highest germination (86\%) after 30 days of experiment followed by $200 \mathrm{ppm}$ gibberellic acid $(84.33 \%)$ and 1000 ppm ethrel (80.67\%). Least germination $(19.0 \%)$ was observed in control. $\mathrm{H}_{2} \mathrm{SO}_{4} 36 \mathrm{~N}$ resulted in maximum in vitro strawberry seed germination and it was statistically at par with $\mathrm{H}_{2} \mathrm{SO}_{4} 30 \mathrm{~N}$. Minimum number of days (2.00) to 50 per cent germination was also recorded with 36 $\mathrm{N} \mathrm{H}_{2} \mathrm{SO}_{4}$. Maximum number of days (7.00) was taken by the lowest concentration of $\mathrm{H}_{2} \mathrm{SO}_{4}$.

\section{Introduction}

Strawberry is a new crop included in the fruit crop cultivation scenario of HP along with other temperate fruits as an effective intercrop and also ensures regular and consistent crop production and return from sale of both fruits and runners. With increase in the demand, the productive fruit cultivars are being evaluated especially the day-neutral type, which flower and fruit over a prolonged time period. Further efforts are being made to introgress the ever bearing trait to the established cultivars like Chandler, Gorella, Douglas, Seascape etc. For any successful crop improvement venture through breeding programme associated with genetical studies it is imperative to have relatively high percentage of seed germination so that seedling size for growth parameter are largely similar. Scott and Ink (1955) based on their study on strawberry seed germination have pointed out that time of emergence of strawberry seedlings may vary from 90-140 days in the same lot from the date of seeding.

This has been further proved by Powers (1945) who showed wide spread variation in time of seed germination for prolonged time period even under controlled conditions in germination chambers. Irregular and delayed 
germination is a prime hindrance especially in soft and small fruits like strawberry, blueberry, raspberry etc. where uniform seedling growth is needed otherwise germination seedling resides total time lag, the hybrid seedlings being from the same cross appear to be of different ages, thus hindering correct assessment of the seedlings. Apart from this poor seed germination imposes a serious problem in the improvement of strawberry through hybridization. With a view to develop day neutral cultivars, hybrids were developed and to avoid incorrect assessment of the hybrid seedling emphasis was laid to have uniform seed germination. Hence the present investigation was undertaken in the Department of Fruit Science, University of Horticulture and Forestry, Nauni, Solan to improve the germination of hybrid seeds.

\section{Materials and Methods}

Seed from freshly harvested hybrid fruits were extracted by the usual procedure of separating the seeds from the pulp by disintegration using a blender, which was followed by decantation of the seed. The seeds were further washed under the tap water to get the seeds free of the mucilaginous covering over the seed. The seeds were dried on blotting paper and were stored at room temperature for 50 days as a rest period to the seeds for embryo maturation. The chemicals namely potassium nitrate $(0.2 \%)$, ammonium nitrate $(0.2$ and $0.5 \%)$, thiourea (500 ppm), gibberellic acid (100 and 200ppm) and ethrel (1000 and $500 \mathrm{ppm})$ where used for seed germination, the requisite information in respect of chemical and the concentration selected on the basis of published literature. Before treating the seeds with selected chemical the hybrid seed was soaked for 24 hours in distilled water. After overnight of soaking the seeds 50 in number were replicated thrice for treating with each chemical and its selected concentration. The seeds were treated for 24 hours and control seeds were treated with distilled water. After the treatment the seeds were washed with distil water and were later placed in petridishes on moist filter paper kept at a room temperature of $20-22^{\circ} \mathrm{C}$. The petridishes were kept moist by adding few drops of water every day. Emergence of the radicle was taken as the criteria of seed germination. The counts of seed germination were recorded every day and the ones that germinated were taken out and planted in a media comprising of soil + sand + cocopeat.

In second experiment achenes were scarified under sterile conditions in a vertical laminar flow hood for 5 minutes with various concentrations of sulphuric acid $(1,3,12,18$, 24,30 , and $36 \mathrm{~N}$ ) then rinsed 3 times in sterile distilled water during 15 minutes. They were then submitted to slow agitation (10 rpm) during 48 hours insterile distilled water. One achene per tube $\left(\begin{array}{llll}160 & \mathrm{x} & 22 & \mathrm{~mm}\end{array}\right)$ was germinated on a mineral medium of Murashige and Skoog (MS) (1962) solidified with $0.6 \%$ (w/v) agar (Difco). The $\mathrm{pH}$ of the medium was adjusted to 5.6 before autoclaving at $120^{\circ} \mathrm{C}$ for 20 minutes. Tubes were sealed with a cotton wool plug covered with a single layer of aluminium foil.

\section{Results and Discussion}

The effect of different chemical treatments on strawberry seed germination is given in Table 1. The observation on germination after 5 days of treatment showed that seeds treated with ethrel $5000 \mathrm{ppm}$ had significantly higher germination $(18.67 \%)$ per cent followed by ethrel $1000 \mathrm{ppm} \mathrm{(13.00 \% )}$ and $200 \mathrm{ppm}$ gibberellic acid $(10.33 \%)$. On the other hand no germination was recorded in the treatments 0.2 and 0.5 per cent ammonium nitrate and control. Germination per cent with ethrel 1000 (34.51\%) and $5000 \mathrm{ppm}(36.00 \%)$ were statistically at par with each other after 10 days. Similar germination percentage 
$(30.00 \%)$ was recorded with the two gibberellic acid treatments i.e. at 100 and 200 ppm. The next best treatment was 0.2 per cent potassium nitrate which had germination up to 26.33 per cent. However only 5 per cent seed germination was reported with control. Ethrel5000 ppm showed significantly higher germination per cent over other treatments after 15, 20 and 25 days. After 30 days 86 per cent germination was recorded with 5000 ppm ethrel followed by 200 ppm gibberellic acid $(84.33 \%)$ and 1000 ppm ethrel (80.67\%).The treatments 0.2 per cent potassium nitrate and 100 ppm gibberellic acid were statistically similar. Least germination (19.0\%) was observed in control.

Table 2 showed the effect of 5 minute treatment with sulphuric acid onin vitro strawberry seed germination percentage. Germination starts from the first week after sowing for achenes treated by $\mathrm{H}_{2} \mathrm{SO}_{4} 24,30$ or $36 \mathrm{~N}$ and only during the second week for those treated with the low concentrations. Similarly, as the concentration of the acid increases, the corresponding germination percentages get higher. Thus, the best germination percentages were obtained following treatment with $\mathrm{H}_{2} \mathrm{SO}_{4} 36 \mathrm{~N}$ and it was statistically at par with $\mathrm{H}_{2} \mathrm{SO}_{4} 30 \mathrm{~N}$. Minimum germination percentage was recorded with $3 \mathrm{~N} \mathrm{H}_{2} \mathrm{SO}_{4}(69.67 \%)$ and it was statistically similar with $1 \mathrm{~N} \mathrm{H}_{2} \mathrm{SO}_{4}(71.00 \%)$. Minimum number of days (2.00) to 50 per cent germination was recorded with $36 \mathrm{~N}$ $\mathrm{H}_{2} \mathrm{SO}_{4}$. Next lower germination percentage was recorded with $30 \mathrm{~N} \mathrm{H}_{2} \mathrm{SO}_{4}$ and it was statistically similar to $24 \mathrm{~N} \mathrm{H}_{2} \mathrm{SO}_{4}$. Maximum number of days (7.00) was taken by the lowest concentration of $\mathrm{H}_{2} \mathrm{SO}_{4}$.

Strawberry seeds are generally sown after stratification though they can germinate without stratification but the germination percentage is very low. Direct sowing of the seeds immediately after extraction from the fruits give poor germination. Among the different chemical treatments tried to improve germination percentage ethrel and gibberellic acid were found to be most effective in improving the germination of unstratified strawberry seeds. The growth regulating properties of ethrel is known to be due to its ability to stimulate ethylene production in plant tissues (Edgerton and Blanpied, 1968). Stimulation of seed germination and seedling growth by ethylene treatment has also been reported in a number of non-dormant seeds (Balls and Hale, 1940). Iyer et al., (1970) documented that a 24 hour pre-treatment with ethrel at concentrations of 1000, 2500 and 5000 ppm gave progressively higher amount of germination with seeds from 'Gorella'. Similarly, Child (1969) investigated the effect of ethrel on strawberry seed germination. Soaking the seeds for 24 hour in concentration of 25,250 and $2500 \mathrm{ppm}$ increase in the amount and rate of germination were obtained even with seeds of Axbridge Early which is known to be normally among the most difficult to germinate.

Treating the seeds with gibberellic acid seems to have substituted the after-ripening in strawberry seeds, giving 84.33 and 70.33 per cent with 100 and $200 \mathrm{ppm}$ respectively. Chellappa (1959) reported that seed dormancy was partially broken in Blakemore, Bremier and Armore cultivars of strawberry. Negi and Singh (1972) observed 40-44 per cent germination of strawberry seeds with gibberellic acid treatment. After a short period (18 days) of chilling treatment, gibberellic acid at $100 \mathrm{ppm}$ promoted significant increase in germination of Freya and Vigour (Thompson 1969). Thiourea treatment has also been reported to be able to affect afterripening in the seeds of peach (Tukey and Carlson, 1945), grape (Randhawa and Negi, 1964). In the present study potassium nitrate $(0.2 \%)$ also significantly $(70.67 \%)$ increased the germination percentage. 
Table.1 Effect of different chemicals on strawberry seed germination

\begin{tabular}{|c|c|c|c|c|c|c|}
\hline \multirow[t]{2}{*}{ Treatment } & \multicolumn{6}{|c|}{ Percentage of seed germination } \\
\hline & 5 days & 10 days & 15 days & 20 days & 25 days & 30 days \\
\hline $0.2 \% \mathrm{KNO}_{3}$ & 6.00 & 26.33 & 36.33 & 53.33 & 66.00 & 71.67 \\
\hline $0.2 \% \mathrm{NH}_{4} \mathrm{NO}_{3}$ & 0.00 & 9.67 & 15.00 & 22.33 & 30.33 & 38.67 \\
\hline $0.5 \% \mathrm{NH}_{4} \mathrm{NO}_{3}$ & 0.00 & 17.33 & 26.00 & 32.33 & 35.67 & 42.00 \\
\hline 500ppmThiourea & 4.33 & 18.67 & 24.67 & 37.00 & 42.00 & 46.00 \\
\hline 100ppm GA & 8.00 & 30.00 & 41.33 & 55.33 & 61.00 & 71.33 \\
\hline 200ppm GA & 10.33 & 30.00 & 47.00 & 62.00 & 70.67 & 84.33 \\
\hline $1000 p p m$ Ethrel & 13.00 & 34.51 & 51.67 & 69.00 & 76.00 & 80.67 \\
\hline 5000ppm Ethrel & 18.67 & 36.00 & 55.00 & 76.00 & 81.33 & 86.00 \\
\hline Control & 0.00 & 5.00 & 10.67 & 14.00 & 17.00 & 19.00 \\
\hline CD at $5 \%$ & 0.99 & 1.76 & 1.79 & 1.76 & 1.66 & 2.05 \\
\hline
\end{tabular}

Table.2 In vitro germination percentage of strawberry seeds scarified with different $\mathrm{H}_{2} \mathrm{SO}_{4}$ concentrations for 5 minutes

\begin{tabular}{|c|c|c|}
\hline $\mathrm{H}_{2} \mathrm{SO}_{4}$ Concentration & $\begin{array}{c}\text { Final germination after } 16 \\
\text { weeks }(\%)\end{array}$ & $\begin{array}{l}\text { Time to } 50 \% \text { of final } \\
\text { germination (weeks) }\end{array}$ \\
\hline $1 \mathrm{~N}$ & 71.00 & 7.00 \\
\hline $3 \mathbf{N}$ & 69.67 & 5.67 \\
\hline $12 \mathrm{~N}$ & 75.33 & 5.00 \\
\hline $18 \mathrm{~N}$ & 80.00 & 4.67 \\
\hline $24 N$ & 86.33 & 3.33 \\
\hline $30 \mathrm{~N}$ & 94.00 & 3.00 \\
\hline $36 \mathrm{~N}$ & 94.33 & 2.00 \\
\hline CD $0.05 \%$ & 1.22 & 0.66 \\
\hline
\end{tabular}

Ammonium nitrate pre-treatment resulted in 44-48 per cent germination (Negi and Singh, 1972). Treatment with ammonium nitrate also enhances germination over control. In Agrostis tenuis (Anderson 1946) and mint (Ikeda and Nakamura 1956) also nitrate ions have been reported to be effective in breaking dormancy. Similar results were reported by Srinivasulu and Murhty (1967) by the use of these two chemicals.

The effect of the sulphuric acid concentrate can be explained by the fact that it softens the teguments making them more permeable to water and gases, which overcomes the dormancy process and starts the physiological one of germination. The results are in agreement with those of Peacock and Hummer (1996) who studied the effect of liquid nitrogen and sulphuric acid on the germination of six species of Rubus. Whereas the liquid nitrogen treatment did not have a significant effect on germination percentage compared to controls, the sulphuric acid increased significantly this rate within four species. A 5 minutes scarification with $\mathrm{H}_{2} \mathrm{SO}_{4}$ $36 \mathrm{~N}$ gives the best germination percentage. The longer the achenes are in contact with sulphuric acid, the more reduced the germination percentage is; this is undoubtedly 
related to the destruction of achenes following the aggressive treatment.

\section{References}

Anderson A M (1946) The effect of light, temperature and potassium nitrate on the germination of Agrostis tenuis (var. High land) seed. Proc. Assoc. Seed Anal. 36:112-25.

Balls A K and Hale W S (1940). The effect of ethylene on freshly harvested wheat. Cereal Chemistry. 17: 490.

Chellapa $\mathrm{T}$ (1959). The physiology of strawberry seed germination. Diss. Abstr 20:859-60.

Edgerton L J and Blanpied G D (1968) Regulation of growth and fruit maturation with 2-chloroethane phosphoric acid. Nature 219:1064.

Hamdouni E M EL, Lamarti A and Badoc A (2001) In virto germination of the achenes of strawberry (Fragaria $x$ ananassa Duch.) cvs 'Chandler' and 'Tudla'. Bull. Soc. Pharm. Bordeaux.140:31-42.

Ikeda N and Nakamura M (1956) Effects of various treatments on the germination of mint seeds. Sci Rap Fac Agric Okavama Univ 9: 39-45.

Iyer C P A, Chacko E K and Subramanyam M D (1970) Ethrel foe breaking dormancy of strawberry seeds. Curr. Sci. 39:27172 .
Negi S P and Singh R (1972) Effect of different chemicals on germination of strawberry seeds. Indian J Hort 29:26568.

Peacock D N, Hummer K E (1996) Pregermination studies with liquid nitrogen and sulphuric acid on several Rubus species. Hort Sci 31 (2):238-39.

Powers L R (1945). Strawberry breeding studies involving crosses between the cultivated varieties (Fragaria $x$ ananassa) and the native Rocky Mountains strawberry (F.ovalis) J.Agr.Res.70:95-122.

Randhawa G S and S S Negi (1964) Preliminary studies on seed germination and seedling growth in grape. Indian $J$ Hort. 21:186-96.

Scott D H and Ink D P (1955). Treatments to hasten the emergence of seedlings of blueberry and strawberry.Proc.Am.Soc.Hort.Sci.66:23 7-42.

Srinivasulu K and Murthy K S (1967) Efficiency of different methods for breaking dormancy in rice seed. Indian J Pl. Physiol. 10:139-42.

Thompson P A (1969). The use of chilling and chemical treatments to promote rapid germination of strawberry achenes. J. Hort. Sci. 44:201-10.

Tukey H B and Carlson R F (1945) Breaking the dormancy of peach seed by treatment with thiourea. Proc. Amer. Soc. Hort. Sci. 46:210.

\section{How to cite this article:}

Suman Lata, Girish Sharma, Sourabh Garg and Munmun Joshi. 2018. Effect of Different Chemical Treatments on Germination of Strawberry Seeds. Int.J.Curr.Microbiol.App.Sci. 7(03): 1270-1274. doi: https://doi.org/10.20546/ijcmas.2018.703.150 